\title{
Morphology of cranial sutures and radiologic evaluation of the variations of intersutural bones
}

\author{
S. Çalışkan' ${ }^{1}$ K.K. Oğuz², S. Tunalı³, M.M. Aldur, B. Erçakmak, M.F. Sargon ${ }^{4}$ \\ ${ }^{1}$ Department of Anatomy, Faculty of Medicine, Ankara Yıldırım Beyazıt University, Ankara, Turkey \\ ${ }^{2}$ Department of Radiology, Faculty of Medicine, Hacettepe University, Ankara, Turkey \\ ${ }^{3}$ Department of Anatomy, Faculty of Medicine, TOBB ETÜ, Ankara, Turkey \\ ${ }^{4}$ Department of Anatomy, Faculty of Medicine, Hacettepe University, Ankara, Turkey
}

[Received: 19 December 2017; Accepted: 1 March 2018]

Background: As far as our literature searches showed us, morphological characteristics of cranium such as sutures, sutural bones and fontanelles had been examined in the skulls in the museums and dry specimens until now. As a modern method, three-dimensional virtual reconstruction of cranial bones by using multidetector computed tomography-computed tomography angiography (MDCT-CTA) can display in vivo morphological characteristics. In our study, we aimed to determine the presence and incidence of these morphological characteristics that can be clinically significant in our population, by using radiologic methods.

Materials and methods: We examined head and neck regions of 185 patients via MDCT-CTA. We evaluated radiologically detectable variations of the metopic sutures, lambda, bregma, asterion and pterion, which can be very easily confused with fractures. Additionally, the differences between the genders and incidence of coexistence of these variations were evaluated.

Results: According to our study, the incidence of persistent metopic suture was $8.1 \%$ and the incidence of lambda variations was 5.9\%. Variations were most commonly encountered on the left asterion, and least commonly on the bregma and left pterion. In the evaluation of the coexistence of the parameters and combinations, the Wormian bones located at the right and left asterions were detected. There were no statistically significant differences between genders.

Conclusions: Variations of the sutures and sutural bones can be easily misdiagnosed with the fractures of related bony regions in unconscious patients with multiple traumas. During surgical interventions in these patients, surgeons must take this fact into consideration in order to make differential diagnosis of fractures and intersutural bone variations. (Folia Morphol 2018; 77, 4: 730-735)

Key words: Wormian bones, MDCT-CTA, Inca bone, sutural bones, three-dimensional reconstruction

\section{INTRODUCTION}

Cranium is the osseous structure of the head and also it is the most complex bony structure in the body. While the young adults' craniums consist of 28 separate bones, many of which are paired, the older adults' craniums are composed of 22 bones. Most of these bones are held together by the joints termed as sutures [13]. Sutures and the junctions of sutures undergo a series of morphological changes from birth to adulthood. The ossification of the cra- 
nial bones is incomplete at birth. Most of the bones are united by fibrous or cartilage tissue $[3,4,6,13]$. During all this process, additional ossification centres appear in or near the sutures, which are the potential sites of Wormian bones. Wormian bones (alternative name of sutural bones) are isolated sutural bones which are various in shape and size [13]. While they frequently occur at fontanelles (especially the posterior fontanel) and pterion, the lambdoid suture is the most frequent location of Wormian bones [5, 7]. The isolated sutural bone in lambda is named as 'Os Incae'. The morphological significance of sutural bones is negligible. Sometimes associated with the rapid cranial expansion e.g. hydrocephaly, sutural bones appear in great numbers [13].

Some researches support that sutural bones are associated with central nervous system anomalies. Otherwise, some authors claim that these bones are linked with genetic factors $[10,11]$. Also, osteogenesis imperfecta and cleidocranial dysostosis can be accompanied by Wormian bones [7]. Sutural bones have clinical importance during the interpretation of radiographs of patients with head trauma. In such cases, the radiologists have to make the differential diagnosis between sutural bones and fractures. Sutural bones may also lead to complications in posterior and lateral approaches to the cranial cavity. Therefore, to know the presence and incidence of these structures is essential for neurosurgeons and radiologists $[10,11]$. Persistent metopic suture is another clinically important structure which is present in $0-7.4 \%$ in different populations and it may lead to abnormal development of frontal sinuses [13]. All these morphological features of the cranium had been examined in the craniums that are found in the museums. These anatomical features of cranial structures can also be evaluated on three-dimensional (3D) models reconstructed from computed tomography (CT) scans.

The aim of this study was to recognise the 3D morphology and the incidence of all these clinically important structures in Turkish population.

\section{MATERIALS AND METHODS}

One hundred and eighty-five patients (109 males, 76 females) who underwent dual source multidetector computed tomography (MDCT) were included in this retrospective study. The patients who were younger than 22 years old and those with a history of cranial surgery and trauma were excluded from the study. The MDCT scans were performed with Somatom Sensation 16 Scanner (Siemens Medical Solutions, Erlangen, Germany). The records of the patients were retrospectively reviewed. Cranial and cervical CT scans that were obtained from 16 sliceMDCT were evaluated for each patient. As a routine procedure, CT procedure was explained to each patient before scanning. As all the patients underwent MDCT for vascular imaging, iodinated contrast media had been applied. The images of each patient were re-evaluated and computer-aided 3D reconstructions were performed. Reconstructions were generated at Leonardo Workstation using Syngo 2007 software. Then, 5 images showing the superior, anterior, posterior, right and left lateral sides of the craniums were considered. All of the patients were older than 20 years and none of them had neurosurgical treatment or history of head trauma. No demographic characteristics except the age and sex were mentioned in the study. SPSS for Windows 11.5 software package was used for statistical analysis. The significance of the differences between the groups in terms of gender, was assessed by Student's $t$ test. The categorical variables were examined by using Pearson's $\chi^{2}$ or Fisher's exact $\chi^{2}$ test. $P$ values $<0.05$ were considered as significant.

All the procedures of our study were approved by the Ethical Committee of Hacettepe University Faculty of Medicine on 28 September 2010 (Number HEK: 410-01-2587).

\section{RESULTS}

Of 185 patients included in this study, 109 (58.9\%) were male and $76(41.1 \%)$ were female. The age range of the participants was in between 22 and 91 and median age was 62.7. According to our study the prevalence of persistent metopic suture was $8.1 \%$. Of the 15 patients with metopic sutures, 7 were male and 8 were female $(6.4 \%$ of male and $10.5 \%$ of female patients had metopic sutures; Table 1). This anatomical variation was more often observed in female patients. However, as a result of statistical analysis there wasn't any statistically significant difference between genders. The persistent metopic suture of a patient can be seen in Figure 1. In this study, lambda was found morphologically normal in 174 (94.1\%) patients. Eleven patients had variations in this region. Also, $7.3 \%$ of male and $3.9 \%$ of female patients had variations of lambda. We classified the variants of lambda region as shown in Figure 2. We defined five groups: type A, type B, type C, 
Table 1. Difference of anatomical variations between genders

\begin{tabular}{lccc}
\hline & Male (n= 109) & Female (n = 76) & P \\
\hline Age & $63.3 \pm 13.1$ & $61.7 \pm 14.8$ & 0.433 \\
Metopic suture & $7(6.4 \%)$ & $8(10.5 \%)$ & 0.314 \\
Lambda & & & 0.529 \\
$\quad$ Normal & $101(92.7 \%)$ & $73(96.1 \%)$ & \\
Abnormal & $8(7.3 \%)$ & $3(3.9 \%)$ & \\
Type A & $2(1.8 \%)$ & $1(1.3 \%)$ & - \\
Type B & $2(1.8 \%)$ & $2(2.6 \%)$ & - \\
Type C & $2(1.8 \%)$ & - & - \\
Type D & $1(0.9 \%)$ & - & - \\
Type E & $1(0.9 \%)$ & - & - \\
Pterion-right & - & - & - \\
Pterion-left & - & $1(1.3 \%)$ & 0.411 \\
Bregma & $1(0.9 \%)$ & - & 1.000 \\
Mendosal suture & - & - & - \\
Asterion-right & $8(7.3 \%)$ & $5(6.6 \%)$ & 0.842 \\
Asterion-left & $11(10.1 \%)$ & $8(10.5 \%)$ & 0.924 \\
Coexistent & $8(7.3 \%)$ & $6(7.9 \%)$ & 0.888 \\
variations & & & \\
\hline
\end{tabular}

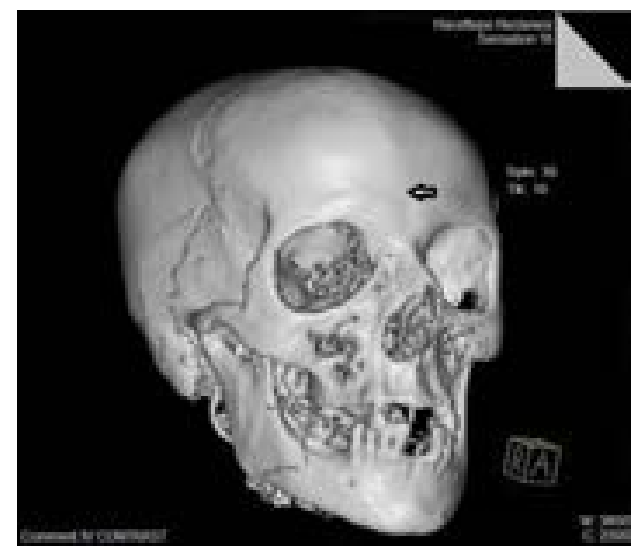

Figure 1. Persistent metopic suture.

type D, type $E$ (Fig. 2). As presented in Table 1, the most commonly found was type B. Of 4 patients in type $B$, 2 patients were male and 2 of them were female (Table 1). Figure 3 presents type $A$, Figure 4 - type $B$, Figure 5 - type $C$, Figure 6 - type $D$ and Figure 7 shows type $\mathrm{E}$.

Of the all patients included in this study, only one female has Wormian bone in left pterion. No Wormian bones were detected in right pterion.

Because the transverse sections that were passing through the vertex were not available in 24 patients' MDCT images, bregma couldn't be evaluated in these participants. As a result of the evaluation of the re-

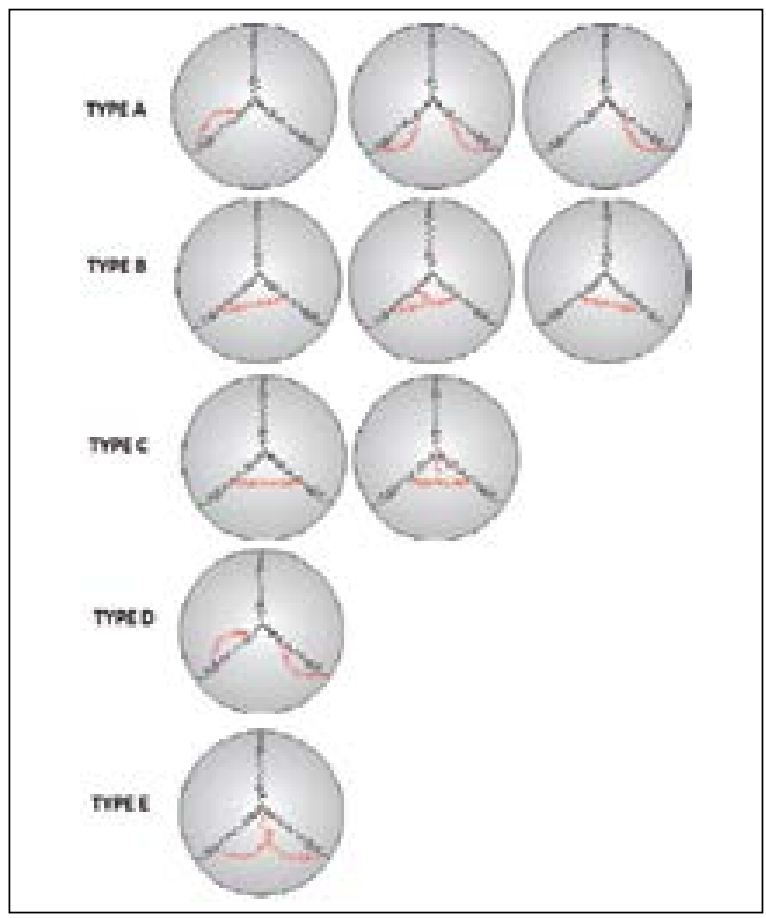

Figure 2. Types of lambda variations.

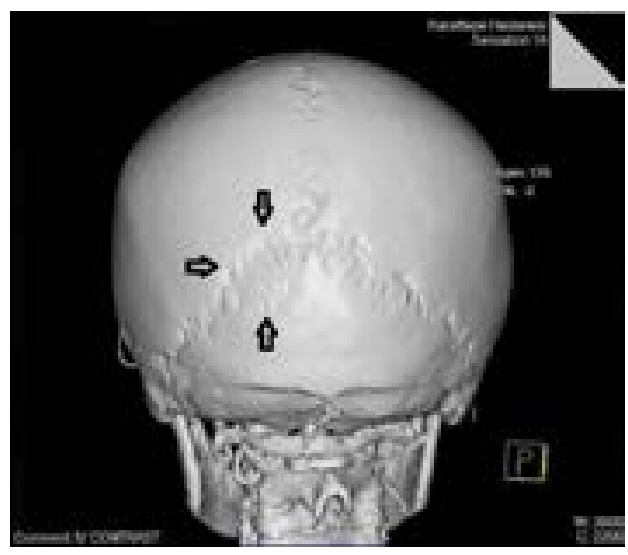

Figure 3. Type A lambda variation.

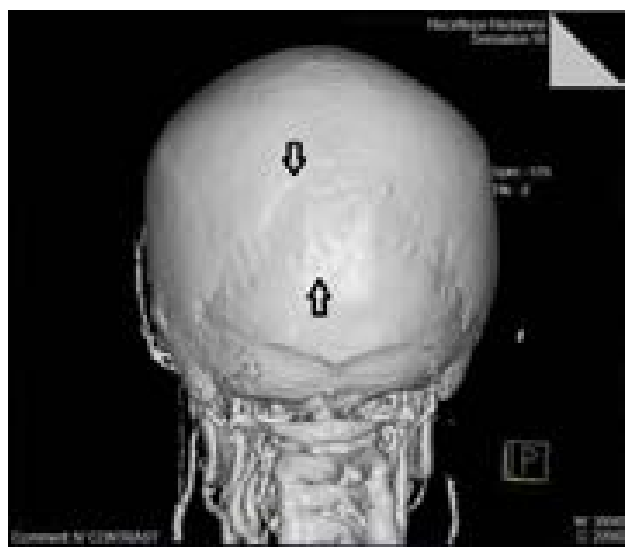

Figure 4. Type B lambda variation. 


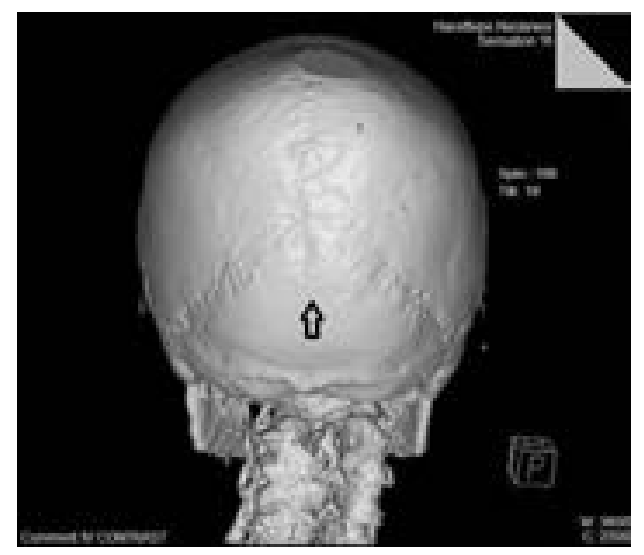

Figure 5. Type $\mathrm{C}$ lambda variation.

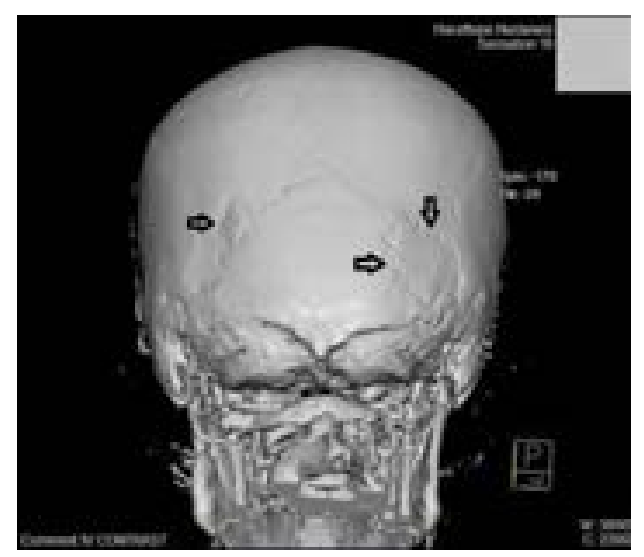

Figure 6. Type $D$ lambda variation.

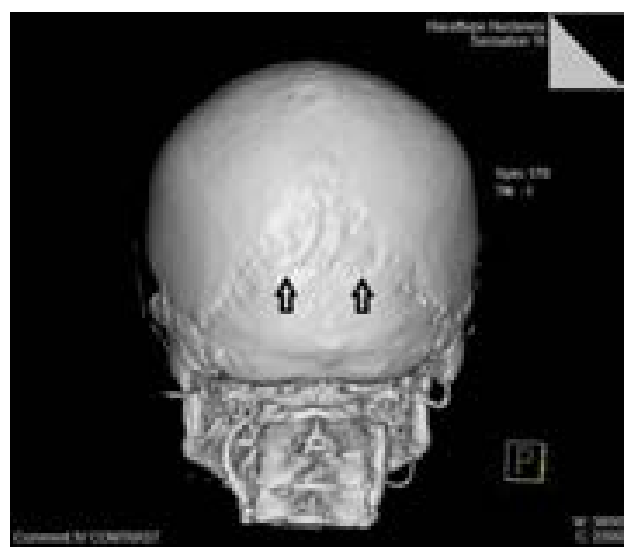

Figure 7. Type E lambda variation.

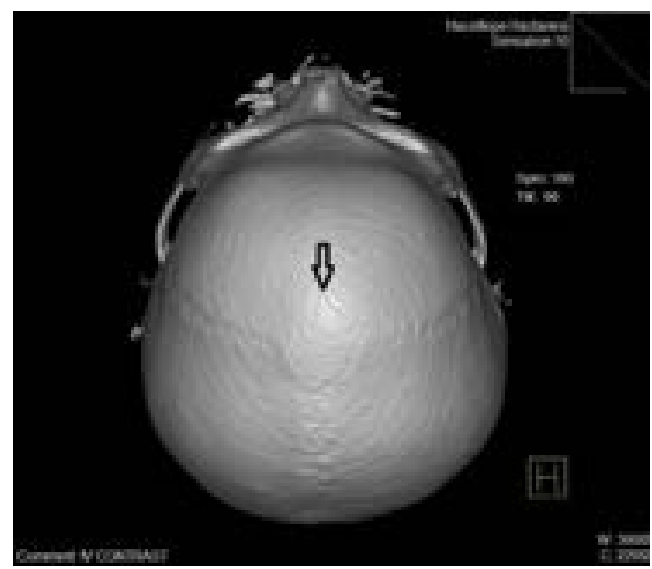

Figure 8. Wormian bone at bregma.

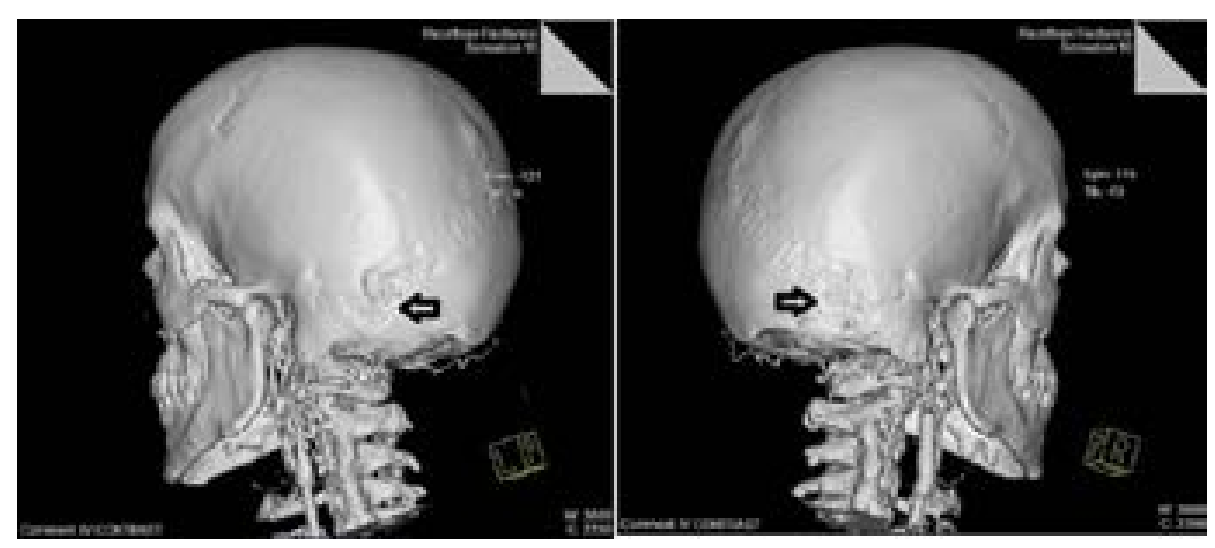

Figure 9. Wormian bones at the right and left asterions of the same patient.

maining 161 patients' vertex images, only one Wormian bone in a male participant was detected (Fig. 8).

We visualised Wormian bones in $13(7 \%)$ patients in right asterion, and in 19 (10.3\%) patients in left asterion. Of 13 patients with Wormian bones in right asterion, 8 were male and 5 were female. Also, of the 19 patients with Wormian bones in left asterion, 11 were male and 8 were female (Table 1). All these results were evaluated statistically and no statistically significant difference was found between genders. Additionally, no statistically significant relationship between age and variations was found. 
Table 2. Frequency of coexistent sutural variations $(n=185)$

\begin{tabular}{ll}
\hline Metopic + asterion-right & $1(0.5 \%)$ \\
Lambda + asterion-left & $1(0.5 \%)$ \\
Bregma + asterion-right & $1(0.5 \%)$ \\
Asterion-right + asterion-left & $9(4.9 \%)$ \\
Metopic + asterion-right + asterion-left & $1(0.5 \%)$ \\
Lambda + asterion-right + asterion-left & $1(0.5 \%)$ \\
\hline
\end{tabular}

Table 3. Difference of coexistent variations between genders

\begin{tabular}{lcc}
\hline & $\begin{array}{c}\text { Male } \\
(\mathbf{n}=\mathbf{1 0 9})\end{array}$ & $\begin{array}{c}\text { Female } \\
(\mathbf{n}=\mathbf{7 6})\end{array}$ \\
\hline Metopic + asterion-left & - & $1(1.3 \%)$ \\
Lambda + asterion-left & - & $1(1.3 \%)$ \\
Bregma + asterion-right & $1(0.9 \%)$ & - \\
Asterion-right + asterion-left & $5(0.9 \%)$ & $4(5.3 \%)$ \\
Metopic + asterion-right + asterion-left & $1(0.9 \%)$ & - \\
Lambda + asterion-right + asterion-left & $1(0.9 \%)$ & - \\
\hline
\end{tabular}

The coexistence of the parameters was also evaluated, and the combinations of two and three of them were found. These combinations were detected in 14 patients. The most common combination was the Wormian bones located at the right and left asterions together, it was found in 9 patients. Triple combinations were seen in 2 patients (Tables 2, 3). All these combinations were consistently accompanied by Wormian bones located at the right and left asterions (Fig. 9).

\section{DISCUSSION}

The aim of this study was to recognise the types and incidence of cranial variations by using MDCT-computed tomography angiography (CTA). In the literature, the studies presenting these morphological variations are found in a limited number of patients. Recent studies were performed on the ancient craniums. Materials were obtained from collections in museums and universities. Therefore, there was no certain information about the age and gender of these skulls except the study of Gümüşburun et al. [1] who examined 302 skulls in Department of Paleoanthropology, Faculty of Language-History-Geography, Ankara University. Of the 302 skulls from the $18^{\text {th }}$ century, $100 \%$ adult and 192 were male. Age and sex characteristics were defined by using anthropometric methods. In our study, the demographic characteristics of 185 patients were defined clearly. Our literature searches showed us that there were no studies about evaluating the coexistence of the variations of bregma, lambda, asterion and pterion. Gümüşburun et al. [1] defined the incidence of each variation but they didn't define the coexistent variations' incidence. Different from the other studies found in the literature, we also evaluated bilateral variations of pterion and asterion regions. While Gümüşburun et al. [1] detected bregma variations in $1.04 \%$ of males, we detected it in $0.9 \%$ of male participants. Both studies defined no bregma variations in female participants. The incidence of lambda variations was found $0.9 \%$ in male skulls by Gümüşburun et al. [1]; in our study, these variations were found in $7.3 \%$ in male participants. In our study, the lambda variations were recorded in 3.9\% female participants but Gümüşburun et al. [1] found no variations in female skulls. Pterion variations were recorded in $11.5 \%$ of male and $7.2 \%$ of female participants. In our study, the incidence was $1.3 \%$ in female participants. For all of the parameters mentioned above, the $p$ values were more than 0.05 in both studies. Also, both studies support each other for the distribution of variations between genders.

Because of its importance as a landmark for surgical approach to transverse sinus, there are studies in the literature related with the asterion variations $[8,9]$. In the study of Satpute and Wahane [9], the incidence of asterion variations was reported to be $9 \%$ in human dry skulls. In another study, the asterion variations had been detected more frequently in females (75\%) than in males (25\%) [12]. In the present study no statistically significant difference was observed in asterion variations between the two genders.

Hanihara and Ishida [2] classified lambda variations in six groups as type I, type II, type III, type IV, type $V$ and 'others'. In our study this classification was as type $A$, type $B$, type $C$, type $D$ and type $E$. Type $A$ in our study was similar to type I, type $B$ was similar to type II, type C was similar to type III, type D was similar to type IV and type E was similar to the 'others' morphologically. Hanihara and Ishida [2] studied lambda variations on 6320 craniums which were collected from osteological or ethnographic collections in museums and universities all around the world. They focused on the distribution and incidence of lambda variations as an ethnological or geographically specific characteristic. In their study, 63 materials were examined from Turkey and lambda was defined as type I variation in all of them. Type I was similar 
to type A in our study. In this study lambda was presented as abnormal in $5.9 \%$ of 185 patients and also type $B$ was the most common type (2.2\%). As it can be seen, both studies did not support each other.

As Hanihara and Ishida [2] defined lambda variations in all of the 63 skulls, we can speculate that skulls exhibited in museums do not reflect the population. Also, artificial cranial deformation can lead to false variations in morphology, too. In our study, participants were randomly selected and morphology of the craniums was evaluated in vivo. For these reasons, we may suggest that the present study is an accurate reflection of the Turkish population. Our study also displays that 3D reconstructed models of CT scans are precious to define in vivo morphological characteristics. This technique may also lead to generating original ideas for further studies about cranium. In 1998, Satheesha [10] reported a case from India. They found 10 sutural bones at the lambdoid suture of a skull during the osteology demonstration for medical undergraduate students [10]. Another case report showing 3 sutural bones in right pterion was presented by Satheesha and Soumya [11]. Both studies were case reports and they do not provide any contribution to the incidence, coexistent variations or differences between genders.

\section{CONCLUSIONS}

In conclusion, different from the other studies found in the literature, this study defined radiologically detectable variations of the metopic sutures, lambda, bregma, asterion and pterion in vivo by MDCT-CTA. This study also contributed to the coexistence of variations. To our knowledge, there is no study in the literature which examined the coexistence of the variations of the intersutural bones in both dry skulls and radiological images. Secondly, this is the first study which examined the coexist- ence of the variations of the intersutural bones in radiological images. These types of variations can be easily misdiagnosed with the fractures of the related bony regions in unconscious patients with multiple traumas. During surgical interventions to these type of patients, the surgeons must always take this fact into consideration in order to make differential diagnosis of fractures and intersutural bone variations.

\section{REFERENCES}

1. Gümüsburun E, Sevim A, Katkici U, et al. A study of sutural bones in Anatolian-Ottoman skulls. Int J Anthropol. 1997; 12(2): 43-48, doi: 10.1007/bf02447895.

2. Hanihara $\mathrm{T}$, Ishida $\mathrm{H}$. Os incae: variation in frequency in major human population groups. J Anat. 2001; 198(Pt 2): 137-152, indexed in Pubmed: 11273039.

3. Junkueira LC, Carneiro J, Kelley RO. Basic Histology. 8th Ed. USA: Mc Graw-Hill Medical Publishing. 2005: 139-140.

4. Leeson TS, Leeson CR, Paparo AA. Text Atlas of Histology. 1.Baskı. Philedelphia: W.B Sounders Company. 1988: 178-179.

5. Meschan I. An Atlas of Anatomy Basic to Radiology. W.B Sounders Company. Philedelphia, London, Toronto. 1975: 230-234.

6. Moore KL, Satterfield TS. Clinically Oriented Anatomy. 3rd Ed. Baltimore: Williams \& Wilkins. 1992: 87-102.

7. Newton Th, Potts DG. Radiology of The Skull and Brain, The Skull, Volume One Book 2. Saint Louis: The C.V. Mosby Company. 1971: 793-800.

8. Rao TR, Rao RS. Anatomical Variation of Asterion in Human Dry Skull- A Case Report. Case Studies Journal ISSN (2305-509X)-Volume 5, Issue 5-May. 2016.

9. Satpute $C$, Wahane A. To study the anatomical variation of asterion in human dry skulls in vidarbha region. Int J Sci Res. 2013 (online): 2319-7064.

10. Satheesha NB. Multipl Wormian bones at the lambdoid suture in an Indian skull. Neuroanatomy. 2008; 7: 52-53.

11. Satheesha NB, Soumya KV. Unusual sutural bones at pterion. Int J Anat Var. 2008; 1: 19-20.

12. Singh R. Incidence of Sutural Bones at Asterion in Adults Indians Skulls. Int J Morphol. 2012; 30(3): 1182-1186, doi: $10.4067 / \mathrm{s} 0717-95022012000300066$.

13. Standring A. Gray's Anatomy, The Anatomical Basis of Clinical Practice. 40th Ed. London: Churchill Livingstone Elsevier. 2008: 409-421. 